\title{
Modernidade e crítica da modernidade: a Sociologia e alguns desafios feministas às categorias de análise*
}

\author{
Silvana Aparecida Mariano*
}

\begin{abstract}
Resumo
Este trabalho aborda as tradições do pensamento sociológico para compreender e explicar a modernidade e seus fenômenos econômicos, sociais e políticos, que transformaram a sociedade moderna ocidental. As discussões em torno dos desafios colocados para a Sociologia para a reformulação das tradições científicas na contemporaneidade foram alavancadas pelas críticas feministas, colocando questionamentos de ordem histórica, epistemológica e metodológica.
\end{abstract}

Palavras-chave: Sociologia, Modernidade, Crítica da Modernidade, Crítica Feminista.

\footnotetext{
* Recebido para publicação em janeiro de 2007, aceito em junho de 2007.

** Doutora em Sociologia pela Universidade Estadual de Campinas. silvanamariano@yahoo.com.br
}

cadernos pagu (30), janeiro-junho de 2008:345-372. 
Modernidade e crítica da modernidade

Modernity and Criticism of Modernity:

Sociology and Some Feminists Challenges to the Categories of Analysis

\begin{abstract}
This paper deals with the traditions of sociological thought in order to understand and explain modernity and its economical, social and political phenomena which have transformed modern western society, as well as the discussions of the contemporary challenges faced by Sociology and by the production of feminist criticism for the reformulation of scientific traditions. This factor present Sociology with historical, epistemological and methodological issues.
\end{abstract}

Key Words: Sociology, Modernity, Criticism of Modernity, Feminist Criticism. 
Silvana Aparecida Mariano

\section{Introdução}

Este trabalho é uma reflexão acerca das tradições do pensamento sociológico para compreender e explicar a modernidade e seus fenômenos econômicos, sociais e políticos que transformaram a sociedade moderna ocidental, bem como as discussões em torno dos desafios colocados para a Sociologia na contemporaneidade pela produção de críticas feministas para a reformulação das tradições científicas.

O objetivo desta análise é demonstrar como fenômenos contemporâneos colocam para a Sociologia questionamentos de ordem histórica, epistemológica e metodológica, bem como o desempenho da crítica feminista para o alargamento da produção de conhecimento no campo das Ciências Sociais em geral e da Sociologia em particular. A reflexão aqui desenvolvida é embasada em análises bibliográficas da produção teórica feminista e de autores e autoras que buscam a renovação do escopo teórico da Sociologia.

A Sociologia é uma forma de conhecimento que se desenvolveu juntamente com a sociedade moderna ocidental, de modo que esta ciência $e$ a modernidade constituíram-se mutuamente. As transformações ocorridas na sociedade, sobretudo no século XIX, em decorrência das Revoluções Industrial e Francesa, colocavam a sociedade como "problema" de análise e explicação e demandavam a formação de uma nova ciência que explicasse as novas condições sociais e seu processo de mudança (Ianni, 1988).

O surgimento da Sociologia é, então, resultado de uma tentativa de compreensão de situações sociais radicalmente novas, produzidas, sobretudo, pelos processos de industrialização e de urbanização. Se a teologia era a forma de conhecimento da sociedade feudal, a Sociologia constitui-se como a forma de conhecimento da sociedade moderna, representando a 
Modernidade e crítica da modernidade

manifestação do pensamento moderno (Castro, 1974; Martins, 1991).

Além da dupla revolução do século XVIII, as mudanças nas formas de pensamento foram outra condição histórica $e$ epistemológica que influenciou o surgimento da Sociologia. As novas formas de pensar representam o desenvolvimento dos ideais iluministas, envolvendo o racionalismo como característica central - racionalismo iluminista -, que buscava romper com a tradição e com a religião. Esse processo produziu a racionalização da vida social, ao mesmo tempo, a Sociologia, como produto desta racionalização, também contribuiu para produzi-la.

Para dar inteligibilidade à modernidade, a Sociologia empenhou-se no desenvolvimento de conceitos como cidadania, democracia, revolução, classes sociais, Estado moderno, nação, indivíduo, sociedade e sujeito, entre muitos outros, que se tornaram constitutivos da própria modernidade. Como afirmam Octavio Ianni e Renato Ortiz, a Sociologia é uma forma de autoconsciência científica sobre a realidade social. Assim, ela é constitutiva da modernidade, na medida em que o mundo moderno que conhecemos é o que está, em grande medida, nos conceitos sociológicos (Ianni, 1988).

Contudo, tomando emprestada a expressão de Carlos Benedito Martins, a Sociologia é também um "projeto intelectual tenso e contraditório", pois convive com explicações diversas sobre a realidade social (Martins, 1991). As tensões mais tradicionais entre os três princípios explicativos fundamentais presentes na Sociologia clássica são: causação funcional, contradição e conexão de sentido, representadas, sobretudo, por Durkheim, Marx e Weber, respectivamente, além de muitos outros pensadores. Em cada um desses princípios encerram-se perspectivas teórico-metodológicas com "diferentes estilos de pensamento, distintas visões da sociedade, do mundo" (Ianni, 1988:12).

Em que pesem as distintas formas de explicação, de acordo com cada abordagem teórica, alguns temas podem ser 
considerados clássicos na Sociologia, expressão de sua tentativa de compreender os fenômenos da modernidade, suas crises e suas transformações - entre eles, sociedade civil e estado nacional, classe social e revolução, ordem e progresso, normal e patológico, racional e irracional, tradição e modernidade, público e privado. De sua dedicação em torno das preocupações sobre como conhecer e explicar a realidade social derivam inquietações metodológicas, com destaque para a clássica questão sobre objetividade e suas implicações no modo de pensar a relação sujeito-objeto na produção do conhecimento científico.

Também podemos destacar como fundamento da Sociologia alguns pressupostos que caracterizam boa parte de suas abordagens, como a oposição entre biológico e social e o uso de pares dicotômicos (oposição binária) para construir os esquemas de explicação.

Não obstante as divergências entre as diferentes abordagens epistemológicas, as categorias de análise e os modelos explicativos tradicionais da Sociologia têm encontrado novos desafios diante do surgimento de novas configurações sociais, especialmente em decorrência do surgimento de novos "sujeitos" sociais. Destaco um fenômeno desse processo: os questionamentos oriundos do surgimento do feminismo como movimento político e pensamento social, que tem colocado em suspenso a validade de muitas categorias com as quais a Sociologia estava habituada a operar. $\mathrm{O}$ objetivo deste trabalho é apontar algumas contribuições do pensamento $e$ das teorias feministas para a renovação do conhecimento sociológico, bem como as dificuldades em obter reconhecimento no campo das disputas teóricas.

\section{O gênero do objeto da Sociologia}

Tratamos na introdução sobre a relação existente entre Sociologia e sociedade moderna, de modo a demonstrar como essa forma de conhecimento está imbricada com determinadas condições históricas, abarcando na idéia de "condições históricas" 
Modernidade e crítica da modernidade

suas implicações econômicas, sociais, culturais e filosóficas. Apontamos também as principais categorias do pensamento sociológico clássico e seus temas recorrentes, igualmente clássicos. Entretanto, esta é apenas uma parte da caracterização que podemos fazer da Sociologia clássica. A literatura que costumamos utilizar nos cursos de introdução à Sociologia no Brasil é geralmente esse o conteúdo que encontramos e que repassamos aos nossos alunos e alunas. Há, no entanto, um "ponto cego" nessa discussão, que remete ao questionamento da construção do objeto da Sociologia e da constituição do sujeito do conhecimento sociológico.

A Sociologia, tal como se constituiu na sua formação, se colocou luz sobre muitos dos fenômenos da sociedade moderna, também contribuiu para a ocultação de alguns deles, incluindo a participação das mulheres e de outros grupos em desvantagens sociais na sociedade e na produção de conhecimento. Se a marginalização da mulher e outros grupos subalternizados, como os negros, não é uma tradição inaugurada pela Sociologia, podemos, ainda assim, dizer que essa tradição não encontrou resistência entre "os pais da Sociologia".

A invisibilidade da participação das mulheres $e$ a marginalização da produção feminina são correspondentes ao caráter androcêntrico ${ }^{1}$ de pensamento, absorvendo do meio social os padrões existentes de dominação masculina $e$ dando-lhes, por vezes, a legitimidade do conhecimento científico. Isso tem ocorrido, historicamente, nas ciências humanas e biológicas história, filosofia, literatura, psicanálise, enfim, nos diversos campos de produção de conhecimento. Portanto, é uma tradição que se expande por diversas áreas e também pelas várias escolas e correntes de pensamento. Neste artigo, estamos no dedicando a pensar esse androcentrismo no âmbito da Sociologia.

1 Androcentrismo: "sistema de pensamento centrado nos valores e identidade masculinos, no qual a mulher é vista como um desvio à norma, tomando como referência o masculino" (Macedo e Amaral, 2005:3). 
Desse modo, os esforços de Durkheim, em fins do século XIX e início do século XX, pela constituição de um status científico da Sociologia o levaram a formular um objeto da Sociologia e um método de investigação. Por essas importantes contribuições, Durkheim é estudado até os dias atuais. No entanto, a Sociologia de Durkheim incorpora o viés sexista, androcêntrico, predominante à sua época, na medida em que toma o homem como ator social.

Estudos feministas mais recentes apontam como Durkheim adotava uma perspectiva minimamente acrítica em torno da subordinação feminina. Jean Elisabeth Pedersen analisa como o autor ao tratar do divórcio desprezava os efeitos do casamento para as mulheres, preocupando-se tão somente com os efeitos para o homem e com a possível relação entre divórcio e suicídio masculino. Para a autora, Durkheim insistia "na diferença sexual como ingrediente essencial para o casamento moderno e a sociedade civilizada" (Pedersen, 2006:s/p).

A defesa da diferença sexual em termos de complementaridade dos papéis socialmente atribuídos a homens e mulheres, bem ao gosto da tradição do pensamento funcionalista, é orientada pela preocupação com a instituição social familiar. Em nome da defesa da família, como um suposto meio de se assegurar a ordem social, postulam-se princípios políticos $e$ teóricos que legitimam a subordinação feminina e, portanto, a dominação masculina. Desse modo, se a situação das mulheres não estava excluída por completo das preocupações de Durkheim, sua condição de subordinação não mereceu qualquer atenção do sociólogo que tanto contribuiu para a conquista do status científico da Sociologia.

Uma justificativa bastante utilizada para os vários pensadores que apresentam as mesmas limitações é que Durkheim era "um homem de seu tempo". No entanto, Pedersen destaca a existência, contemporaneamente a Durkheim, de atividades de mulheres e críticas por elas elaboradas ao pensamento que se produzia naquele momento. A autora defende 
Modernidade e crítica da modernidade

que, de certo modo, existiam condições para pensar outras perspectivas, abrindo possibilidades de incorporar a situação feminina e o olhar das mulheres na constituição dos objetos de interesse acadêmico, como o fez o britânico John Stuart Mill no campo da filosofia (Pedersen, 2006).

Ressalvas semelhantes são também elaboradas pelas teorias feministas a outras duas escolas clássicas da Sociologia, apontando seus limites no tratamento de fenômenos sociais que estão imbricados nas relações de gênero. É provável que as críticas sejam mais direcionadas aos limites dos estudos de Karl Marx, especialmente ao fato de que a classe social, como sujeito histórico, não dá conta dos diferenciais de gênero e da subordinação feminina. $\mathrm{Ou}$, em outros termos, a classe social, tal como entendida de modo clássico, é masculina. Mesmo sendo o mais poupado, Max Weber também não satisfaz essas exigências. Por exemplo, suas tipologias de ação social não incorporam a dimensão das orientações diferenciadas para o padrão de conduta de homens e de mulheres $e$ as tipologias de dominação não dão atenção suficiente para a subordinação das mulheres, embora se inclua o patriarca como tipo ideal da dominação tradicional.

As relações de dominação, em suas várias formas de abordagem, estiveram desde o início dentre os temas privilegiados pela Sociologia. No entanto, isso não foi suficiente para que autores como Émile Durkheim, Max Weber e Karl Marx, clássicos da Sociologia, se preocupassem em observar e explicar as diferentes formas como homens e mulheres estão localizados nas relações de dominação e vivenciam diferentemente essas relações. Eis uma questão de ordem epistemológica, que diz respeito ao modo como conhecemos e o alcance de nossas explicações.

Não basta, entretanto, que se produzam crítica feminista $e$ teorias feministas para iluminar esses "pontos cegos" da tradição sociológica. É necessário, ainda, obter reconhecimento no campo científico sociológico, o que remete a questão a uma outra ordem de obstáculos. Também não basta incorporar, nesse campo, temas valorizados pelos estudos feministas. Importa ainda a perspectiva 
com a qual o tema será tratado. Conforme observa Lia Zanotta Machado (1994: 5), o risco da "naturalização de segundo tipo" está sempre presente.

$\mathrm{Se}$ as teorias sociológicas e antropológicas revelam o caráter social da divisão de trabalho sexual, elas não estão imunes a pagarem o preço de produzirem um segundo tipo de "naturalização": a naturalização derivada da explicação/ compreensão/interpretação da autoridade científica de reafirmar a força do social em atribuir significado à diferença sexual. Ou acaba por produzir um reforço/conformismo frente aos ditames das sociedades, ou produz banalização da idéia de uma sociedade moderna que tende "naturalmente" pelo seu progresso a uma igualdade entre os sexos. Nessa tensão, contra esse segundo tipo de "naturalização", se constitui o campo de estudos de gênero.

Tratamos até aqui da Sociologia clássica, contudo, a Sociologia praticada atualmente ainda apresenta resistências à incorporação das contribuições feministas. Um indicador dessas resistências é o modo como geralmente se ensina Sociologia nas universidades brasileiras, marcada pela ausência de contribuições feministas nas listas de bibliografia das disciplinas ministradas (Adelmann, 2003). Por outro lado, freqüentemente, há o problema de se isolar os estudos de gênero, campo atualmente predominante na produção dos estudos feministas, como uma área temática especializada e não como categoria analítica que oferece contribuições para a reflexão sociológica em torno de várias questões, não apenas os estudos sobre as mulheres. Nessa perspectiva, por vezes, os estudos sociológicos incluem "gênero" como um adendo ou uma ressalva, sem, no entanto, incorporar suas contribuições para a análise.

\section{Contribuições das teorias feministas e dos estudos de gênero para a Sociologia contemporânea}

A teoria sociológica e a teoria social ocidental vêm apresentando, desde a segunda metade do século $\mathrm{XX}$, um 
Modernidade e crítica da modernidade

conjunto variado de questionamentos em torno de seus fundamentos explicativos, métodos de investigação e categorias analíticas, resultando, muitas vezes, em revisões dos cânones estabelecidos. Parte desse processo foi provocada pelo surgimento dos "novos movimentos sociais" e dos "novos atores sociais" que, antes excluídos da produção do conhecimento, a partir da década de 60, representam uma nova voz que se levantava em busca de novas interpretações da história $e$ das relações sociais (Adelmann,2004). Conforme destaca Lia Zanotta Machado (1994), as contribuições entre os diferentes campos de produção científica $e$ os estudos feministas é um movimento de duas vias. Desse modo, há uma dívida reconhecida pelos estudos feministas e, mais recentemente, pelos estudos de gênero entendido como constitutivo dos estudos feministas, para com as contribuições oferecidas pelas tradições disciplinares de áreas como sociologia, antropologia, história, psicanálise, literatura e filosofia.

Podemos igualmente falar em termos de contribuições de teorias sociais para se pensar nas relações de gênero. Nesse caso, o marxismo foi uma importante fonte, na qual os estudos feministas se orientaram para problematizar a desnaturalização das desigualdades entre homens e mulheres. Os estudos feministas tomaram as contribuições do marxismo e, ao mesmo tempo, lhe ofereceram contribuições no sentido de agregar a categoria "gênero" à de "classe social".

Maria Lygia Quartim de Moraes (2000) e Heleieth Saffioti (2000) mostram como a sociedade é constituída por três contradições fundamentais que se reforçam mutuamente: gênero, raça/etnia e classe social. Mesmo apontando os limites do marxismo para a análise das relações sociais entre homens $e$ mulheres, da opressão da mulher $e$ das desigualdades raciais, Saffioti destaca a importância de Marx por ter lhe "ensinado a pensar" sobre o nó "patriarcado-racismo-capitalismo" entendendo-o como uma "realidade contraditória", "também regida por uma lógica igualmente contraditória" (Saffioti, 2000:73). Somando-se às contribuições da Sociologia clássica, autores da 
Sociologia contemporânea e das teorias sociais contemporâneas têm oferecido importante arcabouço para as teorias feministas. Mais recentemente ganham destaque as contribuições do pósestruturalismo para as teorias feministas e o conceito de gênero.

De modo inverso, as contribuições das teorias feministas e dos estudos de gênero não são absorvidas com facilidades pela Sociologia e demais áreas do conhecimento. Como é comum encontramos nas leituras, o reconhecimento da importância política do feminismo no ocidente é mais freqüente que o reconhecimento de suas contribuições para a teoria sociológica. Por vezes, a categoria gênero, quando incorporada aos estudos sociológicos, aparece de forma ilustrativa e sem rigor conceitual. Maria Lygia Quartim de Moraes alerta sobre como essa incorporação é feita por Anthony Giddens em Sociology: a brief but introduction (1986): "a utilização restrita e imprecisa de gênero, como sinônimo de homem e mulher" (Moraes, 1998:101). Ao longo da década de 1990, Giddens foi incorporando com mais precisão o uso da categoria gênero, embora nem sempre ela seja levada em consideração em sua análise, conforme constata Miriam Adelmann (2004).

Gênero, como categoria analítica elaborada nos estudos feministas, tem a função de colocar luz sobre as diferentes posições ocupadas por homens e mulheres nos diversos espaços sociais, dando destaque ao modo como as diferenças construídas socialmente resultam em critérios de distribuição de poder, portanto, em como se constroem as relações de subordinação. Conforme Donna Haraway (2004:209,234),

gênero é central para as construções e classificações de sistemas de diferença. [Ou ainda] gênero é um sistema de relações sociais, simbólicas e psíquicas no qual homens $e$ mulheres são diferentemente alocados.

Gênero é uma categoria de análise que representa para parte do feminismo algo equivalente ao que classe social 
Modernidade e crítica da modernidade

representa para o marxismo. Dessa perspectiva, representa uma ferramenta conceitual que possibilita compreender o modo como as relações de exploração são produzidas e reproduzidas. Alimentados por essas preocupações, os estudos feministas, em suas diferentes abordagens, produziram teorias que lançam alguns desafios e contribuições para os cânones da Sociologia.

Inicialmente - em um processo a contar da década de 1960 - as atividades teóricas das feministas centram-se nos estudos sobre as mulheres. Em meados da década de 1980 crescem os questionamentos no interior das produções feministas, lançando dúvidas sobre seu caráter também universalista e normativo. Feministas negras, feministas pobres e feministas lésbicas apontaram os limites das análises feministas que reproduzem o padrão dos pares binários, dessa vez em termos de sexo/gênero. Entre suas conseqüências, elas enunciam o "heterossexismo compulsório", para usarmos a expressão de Judith Butler (2003), bem como as dificuldades dos feminismos em articular as questões raciais e de classe às questões de gênero. Esse processo conduziu parte dos estudos feministas a privilegiar, na análise, não somente as diferenças entre homens e mulheres - diferenças externas -, como também as diferenças entre as mulheres - diferenças internas (Mariano, 2005).

Gênero, como categoria relacional, adquire nesse contexto maior complexidade e algumas abordagens feministas adotam a posição de defesa da implosão das oposições binárias, universalizantes. De acordo com Donna Haraway (2004:245):

Finalmente, e ironicamente, o poder político e explicativo da categoria 'social' de gênero depende da historicização das categorias de sexo, carne, corpo, biologia, raça $e$ natureza, de tal maneira que as oposições binárias, universalizantes, que geraram o conceito de sistema de sexo/gênero num momento e num lugar particular na teoria feminista sejam implodidas em teorias da corporificação articuladas, diferenciadas, responsáveis, localizadas e com conseqüências, nas quais a natureza não mais seja 
imaginada e representada como recurso para a cultura ou o sexo para o gênero.

Disso resultam mudanças epistemológicas propostas pelos estudos feministas. A problematização do cotidiano, do espaço da experiência, como meio de compreender as razões dos diversos modos de opressão, dando visibilidade a fenômenos que não são, obviamente, transparentes, foi a ponta de lança dos estudos feministas. A penetração do androcentrismo no âmbito da ciência permitia uma relação entre conhecimento e sujeito masculino que não colocava - e muitas vezes ainda não coloca em questão a posição de gênero $e$ demais posicionamentos sociais desse sujeito. Nisso repousava "a idéia da 'objetividade' científica e da 'neutralidade' do sujeito do conhecimento" (Giffin, 2006:637). Assim também ocorria na tradição sociológica. Os estudos feministas instituem, portanto, críticas às noções de "objetividade", "neutralidade" e à relação sujeito/objeto.

A objetividade passaria a ceder mais espaço para a subjetividade, condição necessária para estudos ancorados no cotidiano e na experiência. A neutralidade, se entendida como o conhecimento produzido por um sujeito desinteressado, passaria a ser questionada em seus pressupostos. E o conhecimento, nesses parâmetros propostos, passaria a ser produzido numa relação sujeito/sujeito, na medida em que o sujeito que investiga também lança mão de sua experiência e o sujeito que participa da investigação também integra da produção do conhecimento. Portanto, esse sujeito é situado social e historicamente. Desse modo, há uma crítica fecunda principalmente à ciência binária/objetivista/positivista. Uma das operações desse tipo de ciência é a oposição entre emoção e razão, associadas à subjetividade e objetividade. Trata-se do "mito da investigação imparcial", que é "racista, classista e, sobretudo, masculinista" (Jaggar, 1997:172 apud Giffin, 2006:640) e, podemos acrescentar, fundado no heterossexismo. 
Modernidade e crítica da modernidade

Como destaca Lia Zanotta Machado, em resposta às críticas formuladas por Bourdieu ao campo dos estudos feministas, "a novidade deste campo não é a sua temática, mas sim perspectivas de análise" (Machado, 1994:4). Ainda de acordo com a mesma autora, a "inventividade" dos estudos feministas

se assenta na perspectiva da escolha de um olhar situado $e$ nucleado a partir da posição das mulheres na sociedade. Um olhar que pudesse dizer como a sociedade aparece para as posições das mulheres, e não apenas os lugares das mulheres na sociedade. A postura objetiva é reclamada, mas pelo privilegiamento dos olhares das mulheres. Ao mesmo tempo, dá-se a démarche para reintegrar e repensar a subjetividade e o sujeito na construção do objeto de conhecimento (Machado, 1994:14).

Com essa postura de um "olhar situado e nucleado", a posição do sujeito passa a contar na pesquisa, considere-se, por exemplo, quando iniciamos nossas análises contextualizando de que lugar estamos falando. Esse olhar também contribuiu para se atribuir um status mais elevado a estudos sobre temas como divisão sexual do trabalho, trabalho doméstico, violência doméstica, sexualidade, direitos sexuais e reprodutivos, saúde reprodutiva, entre outros. As próprias noções de dominação e subordinação ganharam novos olhares.

Segundo Lia Z. Machado é como se "um novo ângulo de análise estivesse sendo possível pela criação de uma nova "sensibilidade". Não há qualquer reivindicação de que apenas um olhar feminino possa ver a partir desse ângulo" (Machado, 1994:14).

Portanto, não estamos sugerindo, sob nenhuma hipótese, que somente a mulher (ou o olhar feminino) possa desenvolver uma abordagem sociológica que dê conta de uma certa "sensibilidade" sobre a dominação de gênero e a subjetividade dos sujeitos e dos objetos de pesquisa convertidos em sujeitos. Certamente, sociólogos de qualquer gênero têm toda a condição de fazê-lo, quando reconhecem as dívidas da teoria social com o 
campo feminista. Também não estamos sugerindo que mulheres pesquisadoras terão necessariamente tal olhar sobre a realidade investigada. Muitas delas, senão a maioria, costumam aderir aos cânones estabelecidos no seu campo disciplinar.

De qualquer modo, os estudos feministas $e$ as teorias feministas são produzidos, majoritariamente, por mulheres, o que ocorre muito em função da associação entre movimento social e político e conhecimento científico. Essas mulheres são posicionadas em uma multiplicidade de condições sociais constituídas por critérios de classe, raça/etnia, sexualidade, geração e religião. Essa afirmação não implica em adotar certo binarismo para compreender a produção científica de homens e de mulheres. $\mathrm{O}$ pensamento androcêntrico, que produz pontos cegos sobre as relações de gênero pode orientar tanto análises de homens como de mulheres. Isto é, uma visão "masculinista" não é, certamente, exclusividade de homens; da mesma forma, no campo político não temos homem e mulher, mas uma multiplicidade de formas de ser homem e de ser mulher, o mesmo ocorre na ciência e na Sociologia, tomada em particular. Desse modo, a disputa entre teorias no âmbito da Sociologia e de outras áreas disciplinares de conhecimento não é travada entre mulheres e homens, ou entre identidades essencializadas, mas entre os feminismos e os androcentrismos, ambos com sujeitos contingentes.

Como destaca Lia Z. Machado, o parâmetro explicativo para a formação de redes de pesquisadores/as e pensadores/as, no campo dos estudos feministas, não é a pertença a uma identidade, dentre as diferentes identidades feministas, mas sim o reconhecimento de uma "dívida com os feminismos face ao novo quadro de interrogações postas pelas feministas" (Machado, 1994:6).

Sobre o conhecimento feminista localizado $e$ o conhecimento tradicional objetivo e neutro, a autora afirma: 
Modernidade e crítica da modernidade

A perspectiva feminista introduz e exige a construção do objeto a partir de um olhar situado. Seja situado a partir de um "olhar da mulher", de "olhares de múltiplas mulheres nas suas diferenças de raça, cultura e opção sexual", a partir do "olhar feminino" ou a partir dos "múltiplos olhares femininos". Como o feminino na cultura científica tradicional jamais foi constituído como o paradigma do neutro, o sujeito que se diz metodologicamente feminino e/ou feminista jamais passará por uma fala neutra, não podendo repetir o feito da visão masculina que propicia o contínuo deslizamento entre masculino e neutro. A sua mera introdução produz uma impossibilidade de alçar o gênero do cientista a paradigma da humanidade. Está interditada a identidade entre o "criador-cientista" e o "objeto criado-realidade reconstruída". $\mathrm{Na}$ discursividade dominante da ciência, a humanidade não pode ser lida pelo paradigma do feminino, isto é, pelo acesso privilegiado do feminino ao neutro. O sujeito feminista por estar em contraponto com a discursividade dominante de gênero faz situar tanto o neutro como o masculino como diferentes dele mesmo e descolados entre eles (Machado, 1994:22).

As teorias feministas que defendem o pressuposto de que o sujeito, marcados por diferenças de gênero, raça/etnia, sexualidade, classe social, geração, entre outras, está implicado no conhecimento que produz colocam questões de ordem epistemológica para a Sociologia, questões que tratam do que conhecemos e como conhecemos. No entanto, essas contribuições não lograram reconhecimento suficiente para retirar os estudos feministas de uma relativa marginalização. Marginalização esta que apresenta matizes de acordo com tipologias como estudos das mulheres, gênero e feminismo.

Assim, é possível encontramos pesquisadoras que nos dizem que fazem "estudos de gênero" e não "estudos feministas", pois isso as lançaria em um gueto mais restrito. Falar de estudos feministas seria admitir um caráter militante que se associa ao utópico e isso, na tradição científica, é um obstáculo para o exercício da atividade científica, inclusive na Sociologia. A questão 
é tratada "como, se em grande parte, os pensamentos filosófico e científico não tivessem como uma de suas grandes forças propulsoras o pensamento utópico..." (Machado, 1994:6).

Shirley Malcolm, em entrevista concedida a Carmen Silvia Rial, Miriam Pillar Grossi e Betina Stefanello Lima (2006:707), recomenda:

não deixe ninguém marginalizá-la, fazendo-a falar apenas de gênero. Você precisa poder dar uma opinião sobre o resto do conteúdo de qualquer relatório que esteja sendo discutido, pois, no momento em que for identificada como uma 'pessoa de gênero', você perde toda a autoridade como um membro daquele grupo.

Não seria exagero dizer que a mesma recomendação seria válida para a produção do conhecimento sociológico. É como se os estudos de gênero fossem uma área de especialidade restritiva. Tratar de gênero é tratar do outro, eis a razão para que muitas vezes esses estudos sejam conservados nas margens.

Contudo, mais recentemente podemos identificar um maior reconhecimento das teorias feministas em algumas áreas de pesquisa. No caso do Brasil, o crescimento dos estudos sobre temas como reconhecimento, igualdade e diferença têm contribuído para que se traga à cena teóricas feministas como Nancy Fraser, Íris Young e Chantal Mouffe. O XIII Congresso Brasileiro de Sociologia, realizado recentemente ${ }^{2}$, com a temática geral de "desigualdade, diferença e reconhecimento", deu grande destaque à proposta teórica de Nancy Fraser em torno da articulação entre política de reconhecimento e política de redistribuição como forma alternativa para a justiça social.

Esse exemplo conduz a uma observação: os estudos feministas e de gênero são, por definição, um campo de conhecimento multidisciplinar e transdisciplinar, acumulando

2 Congresso realizado no período de 29 de maio a 01 de junho de 2006, em Recife/PE. 
Modernidade e crítica da modernidade

contribuições de inúmeras tradições disciplinares. Essa característica, por vezes, enfrenta dificuldades junto a pesquisadores e pesquisadoras mais habituados aos rigores das divisões disciplinares. Isso também contribui para explicar certas dificuldades para a incorporação desses estudos e teorias nas grades curriculares dos cursos de sociologia ou ciências sociais $e$ nos programas das disciplinas ofertadas em nossas universidades.

A importante contribuição de Teresa de Lauretis (1994) serve para tematizar como a teoria também atua como uma "tecnologia do gênero", no sentido de que funciona como um dos mecanismos que, simultaneamente, produz e reproduz o gênero. Nesse sentido, as teóricas feministas têm revelado que o gênero historicamente exerceu influências nas escolhas e nas abordagens dos cientistas em geral, incluindo a Sociologia. Portanto, a ciência, e conseqüentemente as teorias, têm gênero, um gênero particular, que se pretende universal - o masculino. Isso recoloca, desta vez em outros termos, o debate clássico da Sociologia em torno da separação entre fato e valor, ou entre objetividade e razão, debate este pautado pela defesa da racionalidade moderna:

Em geral, as feministas têm argumentado contra a suposta neutralidade e objetividade da academia, defendendo que o que colocam como aplicável universalmente tem sido invariavelmente válido somente para homens de uma cultura, classe e raça particulares. (...) As noções de "objetividade" e "razão" têm refletido valores de masculinidade em um ponto particular na história (Nicholson, 1990:5, tradução livre).

Ou, ainda, nos termos formulados por Teresa de Lauretis, as teorias disponíveis ou não se preocupam com gênero ou não são capazes de conceber um sujeito feminino e, desse modo, "contêm e promovem certas representações de gênero" (Lauretis, 1994:229), atuando, assim, como uma tecnologia do gênero.

Muitos trabalhos feministas são críticos também às teorias clássicas da Sociologia para compreender a modernidade, 
destacando a crítica à noção de complementaridade entre os papéis sexuais, presente no funcionalismo, que ignora e/ou legitimando a relação de subordinação entre homens e mulheres; a crítica à insuficiência da categoria classes sociais para explicar as relações sociais de gênero e a rejeição à subordinação das questões de gênero às questões de classe, presentes no pensamento socialista; $e$ as críticas a muitas categorias do pensamento liberal, como indivíduo, cidadania e democracia, todas elas referenciadas ao sujeito masculino, branco $e$ proprietário.

A despeito das diversidades de perspectiva, a invisibilidade da experiência feminina e da produção feminista é corrente nos estudos sociológicos. Se essa invisibilidade foi mais patente no período de surgimento e formação da Sociologia, no séc. XIX e início do séc. XX, ela ainda ocorre na Sociologia contemporânea, embora, indubitavelmente, em graus diferenciados. Situação análoga pode ser observada no campo da história, pois a inclusão das experiências das mulheres, geralmente, é para escrever a história da diferença, designar o outro (Scott, 1994, 1998; Bordo, 2000; Louro, 2002), o sujeito que está preso à sua particularidade, que trata de uma especificidade, portanto, algo de interesse menor.

Conforme Joan Scott, para se "modificar a representação de outros grupos deixados fora da história em razão da raça, etnicidade e classe, tanto quanto em razão do gênero", faz-se necessário elaborar uma análise da discriminação que inclua as próprias categorias, examinando-as de um novo ângulo (Scott, 1994:14-5). Entre as categorias sociológicas colocadas sob novo exame pelos estudos feministas, destacam-se as noções de sujeito/identidade, masculino/feminino e público/privado.

Assim, as teorias feministas têm se empenhado para revelar a cegueira do gênero nas teorias.

Enfocando experiências concretas das mulheres nas culturas, na sociedade e na história, os teóricos feministas 
Modernidade e crítica da modernidade

indagaram como a mudança de perspectiva do ponto de vista dos homens para o das mulheres poderia alterar as categorias fundamentais, a metodologia $e$ o entendimento da ciência e da teoria ocidentais (Benhabib e Cornell, 1987:7).

Sobre as teorias políticas que tentam explicar a formação do Estado e da sociedade política, Carole Pateman afirma que as versões sobre o contrato social, para compreender a sociedade moderna, desprezam a questão do contrato sexual, que estabelece o patriarcado moderno e a dominação dos homens sobre as mulheres. O contrato social, nessa perspectiva, apresenta uma ficção política que funda a liberdade individual $e$ universal, encobrindo a existência do contrato sexual e do contrato da escravidão, portanto, das formas de dominação e de submissão. $\mathrm{O}$ indivíduo livre e universal é, na verdade, o homem branco e proprietário (Pateman, 1993).

Fazendo coro com Octavio Ianni (1988: 31),

o indivíduo autônomo, anônimo, independente, livre, senhor do próprio destino foi uma ilusão. Nem no século XIX nem no XX o cidadão chegou a conformar-se como uma realidade social, política e espiritual.

Os estudos feministas colaboram para explicitar as exclusões presentes neste ideal e, ao questionar a dicotomia entre as esferas pública e privada, têm desenvolvido novas abordagens sobre essas esferas. Eles apontam como essa dicotomia associa, de um lado, a esfera pública à racionalidade e ao bem público comum $e$, de outro, a esfera privado-íntima ao amor e afeição $e$ ao interesse parcial, portanto, ao pré ou anti-racional. De acordo com essa mesma lógica binária, o homem é associado ao público e ao racional, logo, a mulher é associada ao privado e irracional, emocional. Assim, o ato de invocar a "condição feminina", o que implica dizer, a subjetividade, para tecer uma análise é, na origem da Sociologia e em certo grau ainda hoje, uma conduta desaprovada pelos parâmetros científicos objetivos, racionais. 
Em decorrência dos efeitos classificadores dessa lógica binária, as teorias feministas dedicaram-se aos questionamentos do próprio sujeito enquanto categoria sociológica. Há décadas, muitos estudos feministas vêm insistindo em sua desconstrução (Mariano, 2005). Um ponto crucial dessa produção, presente nas teorizações de gênero, é a crítica e a rejeição ao essencialismo, conseqüência também do binarismo. Autoras como Chantal Mouffe (1999, 2003), Joan Scott $(1994,1999)$ e Judith Butler (1998, 2003) destacam que a crítica ao essencialismo abandona a categoria de sujeito como a entidade transparente e racional que poderia outorgar um significado homogêneo à ação. Isso nos permite pensar o sujeito como plural, heterogêneo e contingente. Assim, a crítica ao sujeito revela a parcialidade do sujeito masculino como universal e explicita as diferenças no interior de cada gênero, diferenças como as explicitadas por mulheres negras e lésbicas, por exemplo.

No entanto, há um duplo movimento teórico de reconhecer contribuições $e$, simultaneamente, identificar as limitações do iluminismo e do liberalismo para as teorias feministas. De acordo com Claudia de Lima Costa (2000:59),

embora as categorias modernas e valores do Iluminismo tais como direitos, igualdade, liberdade, democracia inicialmente tenham instruído muitos dos movimentos feministas de emancipação, o discurso humanista da teoria moderna, juntamente com suas noções de Sujeito $e$ Identidade intrinsecamente essencialistas, fundacionalistas $e$ universalistas, tendeu a apagar as especificidades (de gênero, de classe, de raça, de etnia e de orientação sexual, etc.) dos diferentes sujeitos que ocupavam outras fronteiras políticas que aquelas do homem branco, heterossexual $e$ detentor de propriedades.

Essas críticas colocam em evidência o fato de que a noção clássica de sujeito estava marcada por particularidades que se pretendiam universais $e$, na medida em que pretendiam 
Modernidade e crítica da modernidade

universalizar as especificidades do homem branco, heterossexual $e$ detentor de propriedades, tornava-se uma categoria "normativa e opressora", para usarmos a definição de Judith Butler (1998, 2003), inclusive quanto à heterossexualidade compulsória, que oprime homens e mulheres. E tornava a mulher e outros grupos oprimidos ausentes ou invisíveis, para usarmos a caracterização dada por Joan Scott $(1994,1998)$.

\section{Pensar diferente sobre as diferenças; ou, manter-se como o Outro}

A despeito da fecundidade da produção teórica feminista, esta ainda permanece, em grande medida, na condição de outro, diante do tipo de reconhecimento e legitimidade que recebe na academia. Guacira Lopes Louro (2002:14) afirma que "a integração das mulheres como sujeito social e político no campo das Ciências Sociais, por vezes representou apenas isso: o acréscimo de um novo sujeito social". Mesmo sendo este um aspecto importante, fica aquém das intenções das teorizações feministas de produzir um efetivo abalo nos paradigmas da Sociologia, e não simplesmente a incorporação das mulheres aos paradigmas vigentes nos diversos campos disciplinares.

Susan Bordo (2000) explica esse fenômeno a partir das implicações decorrentes do uso da alteridade. Ao mesmo tempo em que a condição de invisibilidade impele os sujeitos subordinados a recorrerem à sua alteridade, o uso da alteridade também contribui para a guetização, ou seja, um isolamento entre pares que compartilham a mesma condição subvalorizada. No caso da academia, trata-se de um gueto formado por pesquisadores e pesquisadoras que se dedicam ao mesmo objeto de estudo, estudos feministas e estudos de gênero.

O caráter marcadamente "masculinista" das produções teóricas faz com que as feministas já se insiram nesse campo de poder como o outro, de modo que suas produções raramente gozam do mesmo status científico das teorias produzidas por 
pensadores e pensadoras supostamente neutros. Além disso, mesmo quando pensadoras/es feministas compartilham o mesmo campo teórico com colegas de outras orientações teóricas, ou ainda, quando suas produções precedem as produções destes, os créditos, muitas vezes, serão atribuídos a eles (Bordo, 2000).

No âmbito da Sociologia, o conceito de dominação masculina, apesar de exaustivamente debatido nos estudos feministas, ganhou maior notoriedade e reconhecimento a partir da obra de Pierre Bourdieu (1998). No meio acadêmico brasileiro, Bourdieu passou a ser o teórico da dominação masculina. É como se precisássemos de um teórico de fora do campo feminista para "legitimar" um conceito de origem feminista. O fato de, no Brasil, o livro de Bourdieu ser mais lido e difundido em comparação às teóricas feministas já é um dado para reflexão.

Para Susan Bordo (2000), esta é uma posição exemplar de como o conhecimento produzido por homens e por mulheres goza de diferentes graus de legitimidade. Da mesma forma, entre os estudos de mulheres há diferentes graus de reconhecimento, dependendo de sua localização entre as análises convencionais $e$ as transgressoras. É certo que esse critério - convenção e transgressão - também serve para qualificar as teorias produzidas por homens. Portanto, a transgressão, a crítica aos padrões convencionais de investigação sociológica, explica apenas em parte a relativa marginalização das teorias feministas. Observe-se, por exemplo, que as listas dos "grandes pensadores", "grandes cientistas sociais" e "importantes sociólogos", clássicos ou contemporâneos, são compostas na maioria por homens. Atualmente, as autoras estão muito mais presentes nas indicações bibliográficas, mas sua representação ainda é pequena no conjunto de pesquisadores. Observem-se, ainda, as dificuldades para tradução no Brasil de importantes teóricas feministas. Vê-se, então, que o gênero do autor parece ser um critério incorporado na classificação das obras e em sua difusão.

Aparentemente, as feministas têm "apenas discursado $e$ incomodado até não poderem mais ser 'evitadas' ou 'ignoradas", 
Modernidade e crítica da modernidade

esta posição sugere que as feministas desenvolvem uma crítica especializada, que não talvez não possa ser ignorada, mas cujas implicações são contidas, limitadas e de impacto geral insuficiente para construir um novo conhecimento sobre "o modo como a cultura opera". Isso sugere uma oposição, "ou se trabalha com gênero ou se desenvolve uma crítica de amplo escopo - escolha uma" (Bordo, 2000:11).

Muitas vezes, como Bordo destaca, as próprias feministas acabam por recorrer à "autoridade" masculina a fim de legitimar suas teorias. Disso decorrem duas conseqüências: as produções teóricas feministas são vistas como aplicáveis apenas para as especificidades das mulheres; e o conhecimento produzido pelas feministas fica subordinado às teorizações produzidas por sujeitos masculinos, pois o referencial masculino ainda goza da condição de representar o universal e o neutro. Segundo a autora, é o que ocorre, por exemplo, com as noções de "política do corpo" e de "desconstrução do eu" que, tendo suas origens na crítica cultural feminista, com teóricas feministas, são atribuídas a Michel Foucault e a Jacques Derridá, respectivamente, tornando-se consenso que as feministas tomaram essas críticas de empréstimo, em vez de tê-las produzido (Bordo, 2000).

$\mathrm{O}$ mesmo dificilmente ocorre com o conhecimento produzido por sujeitos masculinos, que gozam de autoridade para falar da humanidade em geral, da cultura em geral, das relações sociais em geral, etc. e, nessa lógica, jamais serão suspeitos de produzirem um conhecimento marcado e limitado pela especificidade de seu gênero. Afinal, este é neutro! $\mathrm{O}$ sujeito feminino, ainda que não adote um conhecimento localizado $e$ feminista, corre o risco de ficar sob suspeita de praticar um olhar generificado e não objetivo.

O debate sobre "objetividade" do conhecimento, clássico das Ciências Sociais, pensa, sem a crítica devida, o masculino como pleno de condições para produzir um conhecimento "objetivo", enquanto o feminino está sempre preso às suas especificidade, diferença e subjetividade. Assim, a dicotomia 
"objetividade" $e$ "subjetividade", ou fato e valor, é sobreposta à dicotomia masculino e feminino. Só é possível refutar estas categorizações hierarquizadas "desconstruindo" as dicotomias sobre as quais se assentam, desmontando sua lógica interna, revelando seus problemas, limitações $e$ fragilidades $e$ as apontando as múltiplas possibilidades de masculino e feminino, de forma a colocar em evidência o caráter parcial e excludente das noções de "objetividade" $e$ "universalidade", tão caras à modernidade.

A modernidade e a crítica da modernidade encerram inúmeras disputas no campo do conhecimento sociológico, entre elas, a disputa dos próprios sujeitos que constroem o conhecimento, marcados por gênero, classe, raça/etnia, geração, orientação sexual e outras diferenças.

Repensar o uso de categorias é parte do próprio desenvolvimento da Sociologia, considerando que seu objeto está em constante transformação, o que exige constantes questionamentos sobre as formas de explicação.

As condições para o reconhecimento das teorias feministas na contemporaneidade, em especial na Sociologia Contemporânea, são muito mais favoráveis do que fora até a primeira metade do século XX. A produção dos sujeitos femininos, de modo geral, cresceu muito nos meios acadêmicos, o que também pode ser compreendido, em parte, como resultado da crítica feminista.

\section{Referências bibliográficas}

ADELMANN, Miriam. Das margens ao centro?: Refletindo sobre a teoria feminista e a sociologia acadêmica. Estudos Feministas, vol. 11, n ${ }^{\circ} 1$, Florianópolis, CFH/CCE/UFSC, jan-jun/2003, pp.284-288.

. A voz e a escuta. Encontros e Desencontros entre a Teoria

Feminista e a Sociologia Contemporânea. Tese de doutorado, Doutorado Interdisciplinar de Ciências Humanas, UFSC, 2004. 
Modernidade e crítica da modernidade

BenHABIB, Seyla e CORNELl, Drucilla. Feminismo como crítica da modernidade: releituras dos pensadores contemporâneos do ponto de vista da mulher. Rio de Janeiro, Rosa dos Tempos, 1987.

BoRDO, Susan. A feminista como o Outro. Estudos Feministas. vol. 8, ${ }^{\circ}$ 1, Florianópolis, CFH/UFSC, 2000, pp.10-29.

BUTLER, Judith. Fundamentos contingentes: o feminismo e a questão do "pós-modernismo". Cadernos Pagu (11), Campinas-SP, Núcleo de Estudos de Gênero-Pagu/Unicamp, 1998, pp.11-42.

. Problemas de gênero: feminismo e subversão da identidade. Rio de Janeiro: Civilização Brasileira, 2003.

CASTRO, Anna Maria de e DiAS, Edmundo F. Introdução ao Pensamento Sociológico.Rio de Janeiro, Eldorado, 1974.

CostA, Claudia de Lima. O feminismo e o pós-modernismo/pósestruturalismo: (in)determinações da identidade nas (entre)linhas do (con)texto. In: PEDRO, Joana Maria e GROSSI, Miriam Pillar. (orgs.) Masculino, Feminino, Plural: gênero na interdisciplinariedade. Florianópolis, Ed. Mulheres, 2000 (1 ${ }^{\mathrm{a}}$ reimprensão), pp.57-90.

De LAURETIS, Teresa. A tecnologia do gênero. In: HollandA, Heloisa Buarque de. Tendências e Impasses: o feminismo como crítica da cultura. Rio de Janeiro, Ed. Rocco, 1994, pp.206-242.

GIFFIN, Karen Mary. Produção do conhecimento em um mundo "problemático": contribuições de um feminismo dialético e relacional. Estudos Feministas, Florianópolis, CFH/CCE/UFSC, vol. 14, n 3, setdez/2006, pp.635-653.

HaRAWAY, Donna. "Gênero" para um dicionário marxista: a política sexual da palavra. Cadernos Pagu (22), Campinas-SP, Núcleo de Estudos de Gênero-Pagu/Unicamp, 2004, pp.201-246.

IANNI, Octavio. A Sociologia e o Mundo Moderno. Série Textos em Ciências Sociais, nº 5, EDUC, 1988.

. Sociologia do Futuro. Primeira Versão, Campinas-SP, IFCH/UNICAMP, 2000, p.5.

LOURO, Guacira Lopes. Epistemologia feminista e teorização social desafios, subversões e alianças. In: ADELMAN, Miriam e SILVESTRIN, Celsi Brönstrup. Coletânea Gênero Plural. Curitiba-PR, Ed. UFPR, 2002, pp.11-22. 
MACEDO, Ana Gabriela e AmARAL, Ana Luísa. Dicionário da Crítica Feminista. Lisboa: Edições Afrontamento, 2005.

MACHADO, Lia Zanotta. Campo Intelectual e Feminismo: alteridade e subjetividade nos estudos de gênero. Brasilia, Série Antropologia, 1994, pp.1-28.

MARIANO, Silvana Aparecida. O sujeito do feminismo e o pósestruturalismo. Estudos Feministas, vol. 13, $n^{\circ} 3$, Florianópolis, CFH/UFSC, set-dez/2005, pp.483-505.

MARTINS, Carlos Benedito. O que é Sociologia. 27 ed. São Paulo, Brasiliense, 1991.

MORAES, Maria Lygia Quartim de. Usos e limites da categoria gênero. Cadernos Pagu (11), Campinas-SP, Núcleo de Estudos de GêneroPagu/Unicamp, 1998, pp.99-105. . Marxismo e feminismo: afinidades e diferenças. Crítica Marxista, no 11, 2000, pp.89-97.

MOUFFE, Chantal. Feminismo, cidadania e política democrática radical. Debate Feminista. Cidadania e Feminismo (Edição especial), São Paulo, Cia. Melhoramentos, 1999, pp.29-47. 2003.

. La paradoja democrática. Barcelona, Gedisa Editorial,

NiCHOLSON, Linda J. (ed.) Feminism and postmodernism. New York and London, Routledge, 1990.

PATEMAn, Carole. O contrato sexual. Rio de Janeiro, Paz e Terra, 1993.

PEDERSEN, Jean Elisabeth. Política sexual em Comte e Durkheim: feminismo, história e a tradição sociológica francesa. Estudos da Religião, 2006 [Tradução Denise Lopes de Souza] (disponível em http://www.pucsp.br/rever/rv1_2006/t_pedersen.htm\#footnote9texto).

RIAL, Carmen Silvia; Grossi, Miriam Pillar e LiMA, Betina Stefanello. Gênero e Ciência: entrevista com Shirley Malcolm. Estudos Feministas, vol. 14, $\mathrm{n}^{\circ}$ 3, Florianópolis, CFH/CCE/ UFSC, setdez/2006, pp.695-708.

SAFFIOTI, Heleieth I. B. Quem tem medo dos esquemas patriarcais de pensamento? Crítica Marxista, n 11, 2000, pp.71-75. 
Modernidade e crítica da modernidade

ScotT, Joan W. Prefácio a Gender and Politics of History. Cadernos Pagu (3) - Desacordos, desamores e diferenças -, Campinas-SP, Núcleo de Estudos de Gênero-Pagu/Unicamp, 1994, pp.11-27.

. A invisibilidade da experiência. Projeto História, $\mathrm{n}^{\circ} 16$, São Paulo, Revista do Programa de Estudos Pós-Graduados em História e do Departamento de História, 1998, pp.297-325.

. Igualdade versus diferença: os usos da teoria pósestruturalista. Debate Feminista. Cidadania e Feminismo (Edição especial), São Paulo, Cia. Melhoramentos, 1999, pp.203-222. 